\title{
Enhancement of Lipid Peroxidation in the Liver of Mice Exposed to Magnetic Fields
}

\author{
Yuzo WATANABE ${ }^{1 *}$, Masayoshi NAKAGAWA ${ }^{2}$ and Yuichi MIYAKOSHI ${ }^{1}$ \\ ' Department of Public Health and Environmental Medicine, The Jikei University School of Medicine, 3-25-8, \\ Nishi-shinbashi, Minato-ku, Tokyo 105, Japan \\ ${ }^{2}$ Magnetobiology Laboratory, Railway Technical Research Institute, Hikaricho 2, Kokubunji, Tokyo 185, Japan
}

Received October 28, 1996 and accepted December 20, 1996

\begin{abstract}
To elucidate the biological effect of static magnetic fields (SMF), we measured lipid peroxidation in the liver, kidneys, heart, lungs and brain of mice exposed to SMF and also evaluated the combined effect of SMF exposure on the hepatotoxicity induced by treatment with carbon tetrachloride $\left(\mathrm{CCl}_{4}\right)$. Lipid peroxidation in the liver was significantly increased by exposure to $4.7 \mathrm{~T}$ of SMF for 3, 6, 24, or $48 \mathrm{~h}$, whereas that in the kidneys, heart, lungs and brain was not changed compared to the control. The combination of $\mathrm{CCl}_{4}$ injection and SMF exposure caused an increase in lipid peroxidation in the liver exceeding that caused by either treatment alone. Furthermore, the increase in activities of both GOT and GPT caused by $\mathrm{CCl}_{4}$ administration were also enhanced by SMF exposure. These results indicate that the exposure to strong SMF induces lipid peroxidation in the liver of mice and enhances the hepatotoxicity caused by $\mathrm{CCl}_{4}$ administration.
\end{abstract}

Key words: Static magnetic field, Lipid peroxidation, Carbon tetrachloride, Hepatotoxicity, Mice

\section{Introduction}

Since the development of electronics, office automation, medical and research instruments, which generated magnetic fields, was widely diffused in recent years, people are frequently exposed to magnetic fields. Recently, strong static magnetic fields (SMF), such as those generated by magnetic resonance imaging (MRI) for medical diagnosis, and nuclear magnetic resonance (NMR) and electron spin resonance (ESR) for instrumental analysis, have been increasingly used. Electro and static magnetic fields are physical, environmental agents that have been shown to produce a variety of responses in cellular and animal studies, including general changes in gene transcription ${ }^{1,2)}$. Exposure to magnetic fields has induced conditioned and unconditioned reflexes, nerve regulation of the cardiovascular system, electric activity in the brain, hormonal regulation, nerve conductivity, healing

*To whom correspondence should be addressed. of wounds, and regenerative processes, cell respiration, blood coagulation, genetic system, growth of neoplasms, animal growth inhibition, promoter activity, elongation of embryogenesis and formation of anomalies ${ }^{1-10}$.

Furthermore, some epidemiological studies have reported an increased incidence of cancer associated with exposure to electromagnetic fields (EMF) ${ }^{1,10-17)}$ but some researchers have concluded that SMF have no effects on animal behavior, such as motor activity and passive avoidance ${ }^{18,19)}$. And research on the safety of SMF has yielded no direct experimental evidence of any acute adverse effects of exposure to SMF up to about $2 \mathrm{~T}$ in humans ${ }^{20}$. Several studies have shown that strong SMF and EMF provoke the development of stress reactions in animals ${ }^{21-25)}$. It has been suggested that the genotoxic potential of certain chemical or ionizing radiation may be affected by co-exposure to magnetic fields ${ }^{26,27)}$. Oxidative stresses such as $\mathrm{X}$-irradiation, UV irradiation and free radical generating substances increase lipid peroxidation and subsequent tissue damage through 
free radical production ${ }^{28-31)}$.

In this study, we measured lipid peroxidation in various mouse tissues of mice exposed to magnetic fields and we also examined the effect of magnetic fields on the hepatotoxicity of carbon tetrachloride $\left(\mathrm{CCl}_{4}\right)$, which is an enhancer of lipid peroxidation.

\section{Materials and Methods}

\section{Animals and chemicals}

Eight-week-old male BALB/c mice were obtained from Japan SLC, Hamamatsu, Japan. Four mice were housed in a cage made of polycarbonate, under specific pathogen-free conditions and given ad libitum access to food and tap water. $\mathrm{CCl}_{4}$ (purity, 99.8\%) and other chemicals were purchased from Wako Pure Chemical Industries, Ltd., Tokyo, Japan. $\mathrm{CCl}_{4}$ was dissolved in olive oil.

\section{Magnetic field exposure system}

A JS-500 superconducting magnet (SCM) (Toshiba Electric, Japan) was used as the SMF generator. The cylinder bore of the SCM was $200 \mathrm{~mm}$ in diameter and $1,475 \mathrm{~mm}$ long. A uniform magnetic field was produced over a 200 $\mathrm{mm}$ area at the center of the bore. One cage (4 mice) was placed in the center of the bore of the SCM, and another cage was placed in another iron-containing cylinder placed in the same temperature-controlled room for use as a sham exposure control free from magnetic effects. The magnetic flux density at the field-exposed cage as measured with a gaussmeter (FW Bell, U.S.A.) was either 3.0 tesla (T: $\mathrm{T}=10,000$ gauss) or 4.7 T. The SCM system was placed in a temperature-controlled $\left(21-23^{\circ} \mathrm{C}\right.$ ) room (Sanyo Electric, Inc., Japan). Humidity in the room was maintained at 45 $55 \%$. Light in the room was controlled with a 24-h cycle of $\mathrm{ON}$ at 0600 and $\mathrm{OFF}$ at 1800 . Light intensity at the edge of the cylinder bore was 250-300 lux, while that inside the cylinder bore was low but it was impossible to measure the light intensity in the area where the animals were placed because a photocell illuminometer (SPI-1, Toshiba Corporation, Japan) could not work inside either 3.0T or 4.7T SMF. Light intensity in the room was measured with a photocell illuminometer. The atmosphere in the cylinder was circulated with flowing air. The mice in the cages were given free access to food and tap water during the exposure.

\section{Treatments}

After seven days of acclimation to their cages, the mice were randomized into control and experimental groups of four mice each. The groups of mice were exposed to SMF ( 3.0 or $4.7 \mathrm{~T}$ ) for $1,3,6,24$ or $48 \mathrm{~h}$, respectively. Another group of mice were given a s.c. injection of $\mathrm{CCl}_{4}(0.5 \mathrm{ml} /$ $\mathrm{kg}$ ) or olive oil and immediately exposed to $4.7 \mathrm{~T}$ of SMF for $24 \mathrm{~h}$. The blood, liver, kidneys, heart, lungs and brain were removed from each mouse under diethylether anesthesia after exposure. The blood was collected in heparinized tubes from the heart for analysis of the activities of glutamicoxaloacetic transaminase (GOT) and glutamic-pyruvic transaminase (GPT).

\section{Analysis}

Lipid peroxidation in various tissues was determined by quantifying the thiobarbiturate-reactive substances (TBARS) by the methods of Ohkawa et $_{\text {al }}{ }^{32)}$ The level of TBARS was expressed as nmol malondialdehyde (MDA)/g tissue. The activities of GOT and GPT in the plasma, as indicators of hepatotoxicity, were measured with the GOT-UV and GPTUV Test reagents (Wako Pure Chemical Industries, Ltd., Tokyo), respectively. The data were analyzed by the Student's $t$-test.

\section{Results}

The effect of SMF exposure on the lipid peroxidation in the various tissues was estimated by the TBA-RS level. Figure 1 shows the TBA-RS levels in the liver, kidneys, heart, lungs and brain of mice exposed for $24 \mathrm{~h}$ to SMF at

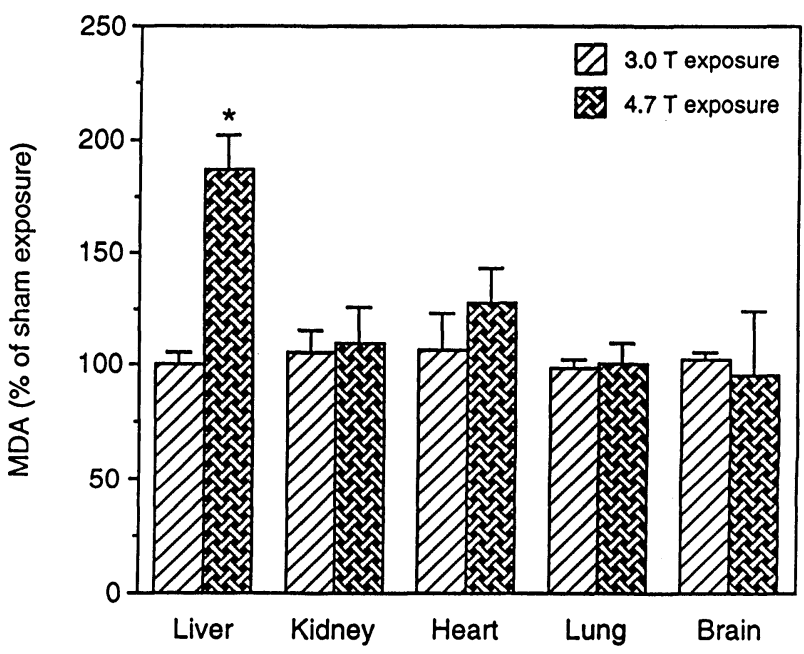

Fig. 1. Lipid peroxidation in various mouse tissues exposed to 3.0 and 4.7 $\mathrm{T}$ of SMF for $24 \mathrm{~h}$

The values are the mean \pm SD for four mice. *Significantly different from the sham exposed control $(\mathrm{P}<0.01)$. 


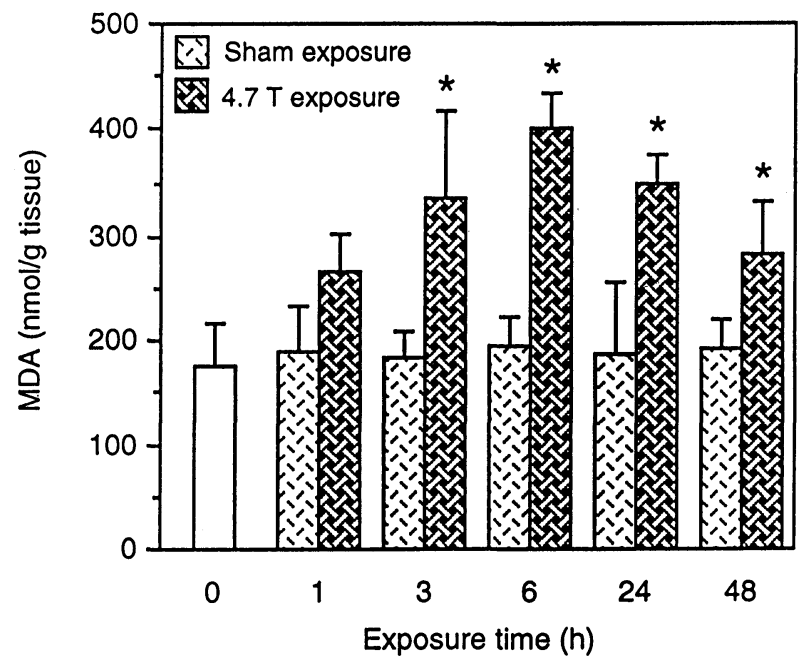

Fig. 2. The effect of 4.7 $\mathrm{T}$ of SMF exposure for various times on the lipid peroxidation in the liver

The values are the mean \pm SD for four mice. $*$ Significantly different from the sham exposed control $(\mathrm{P}<0.01)$.

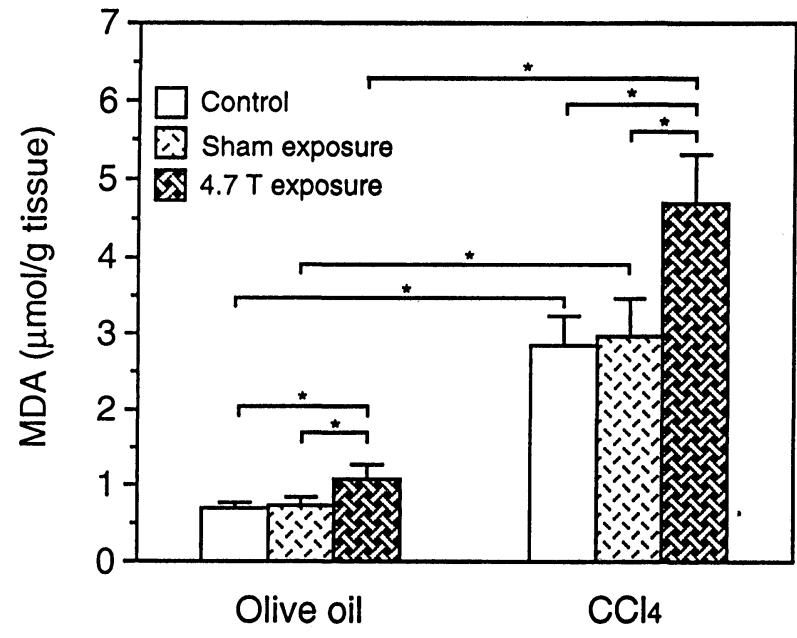

Fig. 3. Effect of $4.7 \mathrm{~T}$ of SMF on lipid peroxidation in the liver of mice treated with $\mathrm{CCl}_{4}$

The values are the mean \pm SD for four mice. ${ }^{*} \mathrm{P}<0.01$.

Table 1. GOT and GPT activities of mice exposed to SMF

\begin{tabular}{|c|c|c|c|c|c|}
\hline \multirow{2}{*}{\multicolumn{2}{|c|}{$\begin{array}{l}\text { Exposure time } \\
\text { (h) }\end{array}$}} & \multicolumn{2}{|c|}{$3.0 \mathrm{~T}$} & \multicolumn{2}{|c|}{$4.7 \mathrm{~T}$} \\
\hline & & \multirow{2}{*}{$\begin{array}{c}\begin{array}{l}\text { GOT } \\
(\mathrm{U} / \mathrm{I})\end{array} \\
35.0 \pm 9.97\end{array}$} & \multirow{2}{*}{$\begin{array}{c}\begin{array}{c}\text { GPT } \\
(\mathrm{U} / \mathrm{I})\end{array} \\
23.3 \pm 7.37\end{array}$} & \multirow{2}{*}{$\begin{array}{c}\begin{array}{c}\text { GOT } \\
(\mathrm{U} / \mathrm{I})\end{array} \\
33.3 \pm 10.40\end{array}$} & \multirow{2}{*}{$\begin{array}{c}\begin{array}{c}\text { GPT } \\
(\mathrm{U} / \mathrm{I})\end{array} \\
22.3 \pm 5.56\end{array}$} \\
\hline 0 & Control & & & & \\
\hline 1 & Sham exposure control & $39.3 \pm 9.07$ & $23.8 \pm 5.38$ & $37.3 \pm 16.09$ & $24.3 \pm 6.55$ \\
\hline 1 & Exposure & $38.0 \pm 9.90$ & $24.8 \pm 8.73$ & $36.8 \pm 8.96$ & $25.5 \pm 4.35$ \\
\hline 3 & Sham exposure control & $34.5 \pm 9.15$ & $23.0 \pm 4.55$ & $41.3 \pm 7.27$ & $24.8 \pm 5.32$ \\
\hline 3 & Exposure & $36.0 \pm 15.12$ & $26.8 \pm 7.72$ & $37.8 \pm 13.12$ & $25.5 \pm 6.66$ \\
\hline 6 & Sham exposure control & $40.5 \pm 8.10$ & $23.0 \pm 3.56$ & $33.3 \pm 12.37$ & $24.0 \pm 4.76$ \\
\hline 6 & Exposure & $40.0 \pm 9.63$ & $23.3 \pm 6.70$ & $33.5 \pm 8.10$ & $21.5 \pm 4.80$ \\
\hline 24 & Sham exposure control & $37.5 \pm 12.61$ & $22.8 \pm 6.34$ & $37.8 \pm 8.46$ & $24.3 \pm 6.08$ \\
\hline 24 & Exposure & $36.5 \pm 10.15$ & $22.5 \pm 7.85$ & $37.8 \pm 8.77$ & $25.0 \pm 4.55$ \\
\hline 48 & Sham exposure control & $38.0 \pm 7.62$ & $21.8 \pm 3.59$ & $34.3 \pm 10.50$ & $25.5 \pm 6.95$ \\
\hline 48 & Exposure & $35.8 \pm 13.50$ & $28.8 \pm 5.38$ & $39.3 \pm 7.63$ & $25.8 \pm 4.86$ \\
\hline
\end{tabular}

The values are the mean \pm SD for four mice.

strengths of 3.0 and 4.7 T. The TBA-RS levels in all of the tissues were unchanged by exposure to $3.0 \mathrm{~T}$ of SMF. In contrast, the $4.7 \mathrm{~T}$ of SMF-exposed mice significantly increased the TBA-RS level in the liver, but not in the kidneys, heart, lungs, or brain.

Lipid peroxidation in the liver of mice exposed to $4.7 \mathrm{~T}$ of SMF for various times was also determined. As compared with the sham exposure mice, the hepatic TBA-RS level was significantly increased following exposure to $4.7 \mathrm{~T}$ of SMF for 3, 6, 24 and $48 \mathrm{~h}$, but not for $1 \mathrm{~h}$ (Fig. 2). Although the increase in the hepatic TBA-RS level was not dependent on the length of exposure to $4.7 \mathrm{~T}$ of SMF, it reached a maximum (approximately 2 -fold increase) at $6 \mathrm{~h}$ of exposure but the TBA-RS levels in all of the tissues of the $3.0 \mathrm{~T}$ of SMF-exposed mice and all the tissues, except the liver, of the 4.7 T of SMF-exposed mice were not significantly different at any of the exposure times from those of the untreated and sham exposed mice (data not shown). The plasma GOT and GPT activities, as indicators of hepatotoxicity, were not affected by exposure to $3.0 \mathrm{~T}$ and 

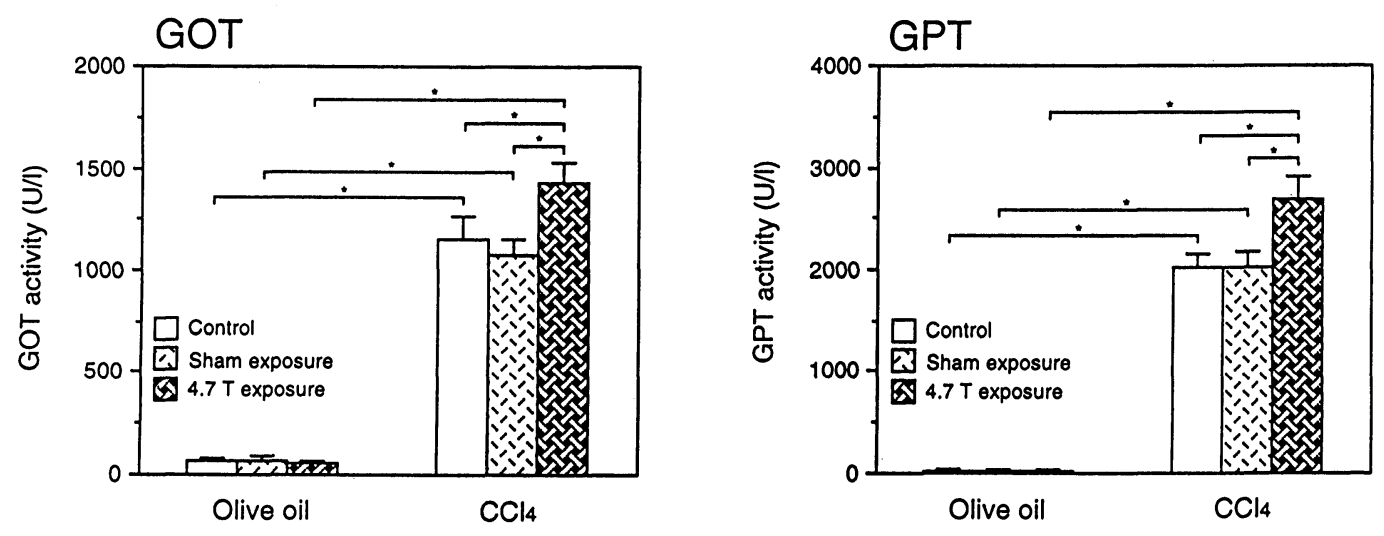

Fig. 4. Effect of $4.7 \mathrm{~T}$ of SMF on the hepatotoxicity of mice treated with $\mathrm{CCl}_{4}$ The values are the mean \pm SD for four mice. $* \mathrm{P}<0.01$.

4.7 T of SMF for any of the exposure times (Table 1).

The TBA-RS levels in the liver of mice subjected to SMF exposure with and without $\mathrm{CCl}_{4}$ treatment are shown in Figure 3. The exposure to $4.7 \mathrm{~T}$ of SMF for $24 \mathrm{~h}$ significantly increased the hepatic TBA-RS level, as in the experiment described above. The hepatic TBA-RS level was also noticeably increased by the injection of $\mathrm{CCl}_{4}$. The TBARS level in the liver of mice immediately exposed to SMF after administration of $\mathrm{CCl}_{4}$ was significantly enhanced compared with that of either SMF alone or the drug alone.

Figure 4 shows the effect of SMF exposure on the liver damage caused by $\mathrm{CCl}_{4}$. The plasma GOT and GPT activities were noticeably increased by $\mathrm{CCl}_{4}$ administration, but not by SMF exposure. The increase in the activities of both GOT and GPT caused by the injection of $\mathrm{CCl}_{4}$ was significantly enhanced by combination with SMF exposure.

\section{Discussion}

Morphological studies have been performed on animals exposed to magnetic fields. Microscopic observation of the brain, adrenals, spleen, bone marrow, heart muscle, skeletal muscles, kidneys, and lungs of animals exposed to magnetic fields did not reveal any changes ${ }^{3,4}$. In hepatocytes, magnetic field exposure induced foamy cytoplasm, an increase in glycogen deposits, and normo-chromatic cell nuclei ${ }^{5}$. Recent electron microscopy studies have shown that magnetic fields exhibited structural changes in hepatocytes, primarily in the mitochondria ${ }^{33,34)}$. This study as well as the morphological reports also showed the biological effect of magnetic fields in the liver, since exposure to strong SMF (4.7 T) increased lipid peroxidation in the liver, but not in the kidneys, heart, lungs, or brain. Parafiniuk et al. have demonstrated that, in hepatocytes, magnetic field exposure induced not only structural changes in mitochondria but also split cell membranes $^{34)}$. It is well known that an increase in lipid peroxidation induces cell membrane damage. These results therefore suggest that magnetic field exposure may cause damage of cell membranes in the liver.

Several studies have shown that various stress reactions are induced in animals exposed to magnetic fields. Exposure to magnetic fields can alter both opioid and non-opioid stressinduced analgesia and day-night rhythms ${ }^{23,24)}$. It has been shown that exposure to SMF increases the growth rate and weight of rats and mice ${ }^{21,22)}$. Tsuji et al. have demonstrated that the food and water intake of mice decreased with exposure to strong $\mathrm{SMF}^{25}$. She has thought the decrease in body weight on the second day was due to a "shock" induced by the SMF. Lipid peroxidation is known to be caused by free radical formation, such as superoxide anion and hydroxyl radical. Exposure to strong SMF may also induce oxidative stress as one of its various stress reactions, because lipid peroxidation in the liver was increased by exposure to strong SMF (4.7 T).

The exposure to 4.7 T of SMF increased the hepatic TBARS level but not the plasma GOT and GPT activities, although $\mathrm{CCl}_{4}$ administration noticeably increased all indicators. On the other hand, the hepatic TBA-RS level increased by SMF exposure was remarkably low compared to the case of $\mathrm{CCl}_{4}$ administration. The plasma GOT and GTP activities may therefore not be affected by the SMF exposure.

In this study, lipid peroxidation induced by a combination of $\mathrm{CCl}_{4}$ administration and strong SMF (4.7 T) exposure was more noticeable than that induced by either agent alone. 
The plasma GOT and GPT activities were also enhanced by combining $\mathrm{CCl}_{4}$ administration with strong $\mathrm{SMF}$ (4.7 T) exposure. The mechanism of the enhancement of liver damage caused by the combination of $\mathrm{CCl}_{4}$ and $\mathrm{SMF}$ is unknown. $\mathrm{CCl}_{4}$ administration was previously shown to increase lipid peroxidation in the liver and then induce hepatotoxicity. $\mathrm{CCl}_{4}$ metabolism is activated by the cytochrom P-450 monooxygenase system, and forms the trichloromethyl radical $\left(\cdot \mathrm{CCl}_{3}\right)$, which then combines with oxygen, forming a much more reactive $\cdot \mathrm{CCl}_{3} \mathrm{O}_{2}$ species ${ }^{30,35}$. These activated species are mainly responsible for the liver damage. The hepatotoxicity caused by $\mathrm{CCl}_{4}$ may be enhanced under the oxidative stress induced by SMF exposure. Further studies are needed to examine the effect of a combination of other free radical generating substances with SMF on lipid peroxidation.

The magnetic flux density generated from MRI and NMR is approximately $1.0-2.0 \mathrm{~T}$ and $2.0-10.0 \mathrm{~T}$, respectively. Furthermore, MRI, which generates stronger magnetic flux density (more than $4.0 \mathrm{~T}$ ), has recently been developed. Since MRI and NMR are now widely used clinically and analytically, patients and operators may be at risk of exposure to strong magnetic fields. These studies suggest that, in humans, lipid peroxidation in the liver may be increased by exposure to the strong magnetic fields generated during MRI or NMR procedures.

\section{Acknowledgments}

The authors sincerely thank Prof. H. Shimizu (The Jikei University School of Medicine) and Dr. M. Sato (National Institute for Environmental Studies) for their encouragement throughout this study. The study was supported in part by a grant from the Ministry of Education, Science and Culture, Japan and the Uehara Memorial Foundation.

\section{References}

1) Sagan L (1992) Epidemiological and laboratory studies of power frequency electric and magnetic fields. JAMA 268, 625-9.

2) Adey WR (1981) Tissue interaction with nonionizing electromagnetic fields. Physiol Rev 61, 435-514.

3) Gorczynska E (1985) Effect of magnetic field on the blood coagulation process in guinea-pigs. ed. by Rocznik PAM, 39-51, Szczecin, PZWL, Warszawa.

4) Bernothy J (1963) Basic concepts related to magnetic field and magnetic susceptibility. In: Biological effects of magnetic fields. 3-38, Plenum Press, NY.

5) Gorczynska E (1985) Dynamics of thrombotic process in the light of pathogenesis of homostasis under conditions of static magnetic field. Rozprawy 96, Akademia Rolnicza, Szczecin.

6) Gorczynska E (1989) Effect of static magmetic field on some enzyme activities in rats. J Hyg Epidemiol Microbiol Immunol 33, 149-55.

7) World Health Organization (1987) Environmental health criteria 69 , magnetic fields. WHO, Geneva.

8) Ahlbom A (1988) A review of the epidemiologic literature on magnetic fields and cancer. Scand J Work Environ Health 14, 337-43.

9) Parry S (1989) Power fragmency field. Depressive illness and myocardinal infarction. Public Health 103, 177-80.

10) Shimizu H, Suzuki Y, Okonogi H (1995) Biological effects of electromagnetic fields. Jpn J Hyg 50, 91931.

11) Savitz DA (1994) Over view of epidemiologic research on electric and magnetic fields and cancer. Am Ind Hyg Assoc J 54, 197-204.

12) Frankel RB (1986) Biological effects of static magnetic fields. In: CRC handbook of biological effects of electromagnetic fields. eds. by Polk C, Postow E, 1808, CRC Press, Boca Raton.

13) Bates MN (1991) Extremely low freqency electromagnetic fields and cancer: The epidemiological evidence. Environ Health Perspect 95, 147-56.

14) London SJ, Thomas DC, Bowman JD, Sobel E, Cheng T-C, Peters JM (1991) Exposure to residential electric and magnetic fields and risk of childhood leukemia. Am J Epidemiol 134, 923-37.

15) Feychting M, Ahlbom A (1993) Magnetic fields and cancer in children residing near Swedish high-voltage power lines. Am J Epidemiol 138, 467-81.

16) Löscher W, Mevissen M (1994) Animal studies on the role of 50/60-Hertz magnetic fields in carcinogenesis. Life Sciences 54, 1531-43.

17) Floderus B, Persson T, Stenlund $C$, Wennberg A, Öst A, Knave B (1993) Occupational exposure to electromagnetic fields in relation to leukemia and brain tumors: A case-control study in Sweden. Cancer Causes Control 4, 465-76.

18) Davis HP, Mizumori SJY, Allen H, Rosenzweig MR, Bennett EL, Tenforde TS (1984) Behavioral studies with mice exposed to $\mathrm{DC}$ and $60-\mathrm{Hz}$ magnetic fields. Bioelectromagnetics 5, 147-64. 
19) Ossenkopp K-P, Innis NK, Prato FS, Sestini E (1986) Behavioral effects of exposure to nuclear magnetic resonance imaging: I. Open-field behavior and passive avoidance learning in rats. Magn Reson Imaging 4, 275 80.

20) McKinlay AF, Allen SG, Dimbylow PJ, Muirhead CR, Saunders RD (1993) Restrctions on human exposure to static and time varying electromagnetic fields and radiation. Ducuments of the NRPB 4, 7-63.

21) Nahas G, Boccalon H, Berryer P, Wagner B (1975) Effects in rodents of a 1-month exposure to magnetic fields (200-1200 gauss). Aviat Space Environ Med 46, 1161-3.

22) Nakagawa M (1980) Food consumption of mice in the static magnetic fields of moderate strength. Jpn J Ind Health 22, 280-1.

23) Kavaliers M, Ossenkopp K-P (1988) Day-night rhythms of opioid and non-opioid stress-induced analgesia: differential inhibitory effects of exposure to magnetic fields. Pain 32, 223-9.

24) Ossenkopp K-P, Kavaliers M, Lipa S (1990) Increased mortality in land snails (Cepara nemoralis) exposed to powerline $(60-\mathrm{Hz})$ magnetic fields and effects of the light-dark cycle. Neurosci Lett 114, 89-94.

25) Tsuji Y, Nakagawa M, Suzuki Y (1996) Five-tesla static magnetic fields suppress food and water consumption and weight gain in mice. Ind Health 34, 347-57.

26) McCann J, Dietrich F, Rafferty C, Martin OA (1993) A critical review of the genotoxic potential of electric and magnetic fields. Mutation Res 297, 61-95.
27) Shein VI (1988) The combined effect of the stationary magnetic field and ionizing radiation. Radiobiologiia 28, 703-6.

28) Horgan VJ, Philpot J (1954) VII. Attempted estimation of organic peroxides in $\mathrm{X}$-irradiated mice. $\mathrm{Br} \mathrm{J}$ Radiol 27, 63-72.

29) Meffert H, Diezel W, Sonnichsen N (1976) Stable lipid peroxidation products in human skin: detection, ultraviolet light-induced increase, pathogenic importance. Experientia 32, 1397-8.

30) Slater TF (1984) Free-radical mechanisms in tissue injury. Biochem J 222, 1-15.

31) Bus JS, Gibson JE (1984) Paraquat: Model for oxidantinitiated toxicity. Environ Health Perspect 55, 37-46.

32) Ohkawa H, Ohishi N, Yagi K (1979) Assay for lipid peroxides in animal tissues by thiobarbituric acid reaction. Anal Biochem 95, 351-8.

33) Makowski J, Oledzka-Slotwinski H, Gonet B (1976) Effect of constant magnetic field on rat hepatocytes. Annal Med Pol Acad Sci 21, 78-81.

34) Parafiniuk M, Gorczynska E, Gutsch A, Parafiniuk W (1992) Effect of constant magnetic field on the liver of guinea pig. Electron microscopic studies. Folia Histochem Cytobiol 30, 119-24.

35) Poyer LJ, Floyd AR, McCay BP, Janzen GE, Davis RE (1978) Spin-trapping of the trichoromethyl radical produced enzymic NADPH oxidation in the presence of carbon tetrachloride or bromotrichloromethane. Biochim Biophys Acta 539, 402-9. 